\title{
2-(Quinolin-4-yloxy)acetamides Are Active against Drug-Susceptible and Drug-Resistant Mycobacterium tuberculosis Strains
}

Kenia Pissinate, $^{\dagger}$ Anne Drumond Villela, ${ }^{\dagger, \dagger}$ Valnês Rodrigues-Junior, ${ }^{\dagger, \S}$ Bruno Couto Giacobbo, ${ }^{\dagger, \S}$ Estêvão Silveira Grams, ${ }^{\dagger}$ Bruno Lopes Abbadi, ${ }^{\dagger, \S}$ Rogério Valim Trindade, ${ }^{\dagger, \S}$ Laura Roesler Nery, ${ }^{\|}$ Carla Denise Bonan, ${ }^{\S, \|}$ Davi Fernando Back, ${ }^{\perp}$ Maria Martha Campos, ${ }^{\dagger, \ddagger, \S}$ Luiz Augusto Basso, ${ }^{\dagger,}, \S$

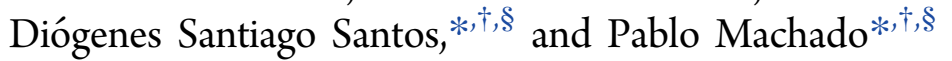

\begin{abstract}
${ }^{\dagger}$ Instituto Nacional de Ciência e Tecnologia em Tuberculose (INCT-TB), Centro de Pesquisas em Biologia Molecular e Funcional, Pontifícia Universidade Católica do Rio Grande do Sul, 90619-900 Porto Alegre, RS, Brazil

*Programa de Pós-Graduação em Medicina e Ciências da Saúde, Pontifícia Universidade Católica do Rio Grande do Sul, 90619-900 Porto Alegre, RS, Brazil

${ }^{\S}$ Programa de Pós-Graduação em Biologia Celular e Molecular, Pontifícia Universidade Católica do Rio Grande do Sul, 90619-900 Porto Alegre, RS, Brazil

"Laboratório de Neuroquímica e Psicofarmacologia, Pontifícia Universidade Católica do Rio Grande do Sul, 90619-900 Porto Alegre, RS, Brazil

${ }^{\perp}$ Departamento de Química, Laboratório de Materiais Inorgânicos, Universidade Federal de Santa Maria, 97105-900 Santa Maria, RS, Brazil
\end{abstract}

Supporting Information

ABSTRACT: 2-(Quinolin-4-yloxy)acetamides have been described as potent in vitro inhibitors of Mycobacterium tuberculosis growth. Herein, additional chemical modifications of lead compounds were carried out, yielding highly potent antitubercular agents with minimum inhibitory concentration (MIC) values as low as $0.05 \mu \mathrm{M}$. Further, the synthesized compounds were active against drug-resistant strains and were devoid of apparent toxicity to Vero and HaCat cells $\left(\mathrm{IC}_{50} \mathrm{~s} \geq\right.$ $20 \mu \mathrm{M}$ ). In addition, the 2-(quinolin-4-yloxy)acetamides

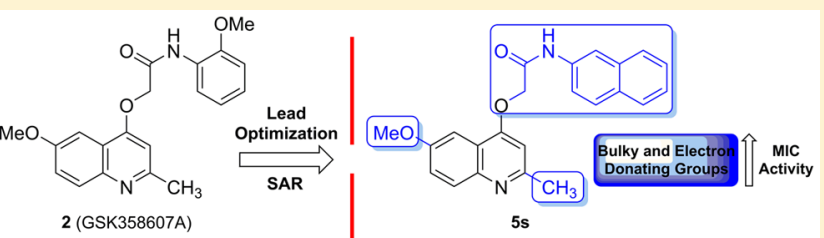

MIC (Mtb H37Rv) $=0.44 \mu \mathrm{M}$

MIC $($ Mtb H37Rv) $=0.05 \mu \mathrm{M}$ showed intracellular activity against the bacilli in infected macrophages with action similar to rifampin, low risk of drug-drug interactions, and no sign of cardiac toxicity in zebrafish (Danio rerio) at 1 and $5 \mu \mathrm{M}$. Therefore, these data indicate that this class of compounds may furnish candidates for future development to, hopefully, provide drug alternatives for tuberculosis treatment.

KEYWORDS: Tuberculosis, quinoline-based compounds, drug-resistant research, SAR

$\mathrm{T}$ uberculosis (TB) is an infectious contagious disease caused mainly by Mycobacterium tuberculosis (Mtb) and is one of the most devastating public health problems worldwide. Approximately 9.6 million new cases claiming 1.5 million lives were reported in $2014 .^{1}$ The emergence of multidrug-resistant TB (MDR-TB) and extensively drug-resistant TB (XDR-TB), ${ }^{2}$ HIV coinfection, ${ }^{3}$ and the lack of effective vaccines have currently placed $\mathrm{TB}$ as the second leading cause of global mortality due to an infectious agent. Further complicating the situation, one-third of the world population have been estimated to carry a latent or dormant phenotype of $\mathrm{Mtb}$. MDR-TB and XDR-TB treatments are limited and recommended medicines are often not available, reducing the treatment success rate and revealing an urgent need for new anti-TB alternatives. ${ }^{5}$ Within this context, in 2012, the United States Food and Drug Administration (FDA) approved bedaquiline (1) for the treatment of MDR-TB in adults when no other therapeutic alternatives were available (Figure 1$)^{6}$

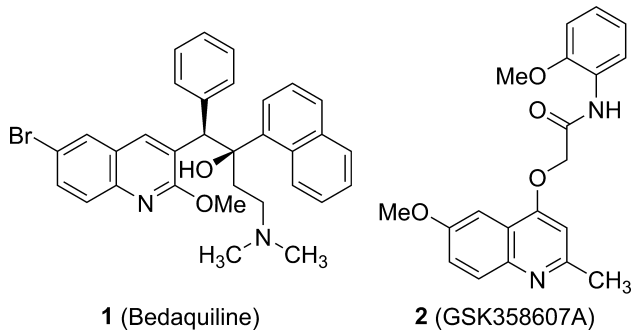

Figure 1. Quinoline-containing compounds.

This diarylquinoline-based drug was the first antitubercular compound approved for clinical use after rifampin, which was introduced in the early 1960s. However, some possible cardiac

Received: August 10, 2015

Accepted: January 11, 2016

Published: January 11, 2016 
side effects attributed to bedaquiline ${ }^{7}$ and the elevated adaptive capacity of $\mathrm{Mtb}$, which culminate with rapid cases of drugresistance, reinforce the need for continuing research efforts to the development of new anti-TB drugs.

Present in the molecular structure of clinically important drugs such as bedaquiline ${ }^{6}$ and some fluoroquinolones, ${ }^{8}$ the quinoline ring has emerged as a privileged scaffold in medicinal chemistry campaigns that are designing novel antitubercular structures. ${ }^{9}$ Incidentally, 2-(quinolin-4-yloxy)acetamides have been described as noncytotoxic compounds endowed with potent inhibitory activity against $M$. tuberculosis $\mathrm{H} 37 \mathrm{Rv}$ in vitro. ${ }^{10}$ These molecules were obtained from phenotypic screening leading to a set of 177 lead-compounds. The lead structure 2 (Figure 1) from the quinoline series exhibited minimum inhibitory concentration (MIC) of $0.70 \mu \mathrm{M} .{ }^{10}$ As part of our ongoing program, we are interested in obtaining novel antimycobacterial compounds that are active against drug-resistant Mtb strains.

In this study, we synthesized a series of 2-(quinolin-4yloxy)acetamides for further evaluation of MICs using drugsusceptible Mtb strains. In addition, the structural requirements for activity of the compounds were investigated in a preliminary structure-activity relationship (SAR) study. The most active molecules against $M$. tuberculosis $\mathrm{H} 37 \mathrm{Rv}$ were tested against a panel of clinically isolated drug-resistant strains and in a macrophage-infected model. Finally, thermodynamic solubility, metabolic stability in human liver S9 fraction, cytochrome P450 inhibition, and cardiotoxicity risk were also evaluated.

The syntheses of 2-(quinolin-4-yloxy)acetamides 2, 5a-o, and $\mathbf{5 q}-\mathbf{t}$ were conducted in two synthetic steps. Our structural modifications were aimed primarily at the creation of a smallmolecule library containing structures with different electronic and lipophilic properties. Accordingly, substituents directly attached to the $N$-arylacetamide group were chosen in an attempt to find chemical groups from maximal quadrants of the Craig plot correlating sigma constants of the Hammett equation $(\sigma)$ and lipophilic substituent constants $(\Pi) .{ }^{11}$ First, the 2-bromo- $N$-arylacetamides $\mathbf{4 a - o}$ and $\mathbf{4 q -}-\mathbf{t}$ were prepared by the acylation reaction of substituted anilines or 1(2)naphthylamine using bromoacetyl chloride in the presence of 4dimethyl aminopyridine (DMAP) as a catalyst, according to a previously described protocol. ${ }^{12,13}$ Subsequently, 2-(quinolin-4yloxy)acetamides $\mathbf{2}, \mathbf{5 a}-\mathbf{o}$, and $\mathbf{5 q}-\mathbf{t}$ were synthesized by the $O$-alkylation reaction of 4-hydroxyquinolines $3 \mathbf{a}-\mathbf{b}$ with 2 bromo- $N$-arylacetamides $4 \mathbf{a}-\mathbf{o}$ and $4 \mathbf{q}-\mathbf{t}$ in the presence of potassium carbonate using $\mathrm{N}, \mathrm{N}$-dimethylformamide (DMF) as the solvent (Scheme 1). The reaction mixtures were stirred for $16 \mathrm{~h}$ at $25{ }^{\circ} \mathrm{C}$ to afford the products with $32-98 \%$ yields.

Notably, 4-hydroxyquinolines $\mathbf{3} \mathbf{a}-\mathbf{b}$ could be easily obtained from the cyclocondensation reaction between anilines and $\beta$ ketoesters; however, these compounds were purchased from suppliers and used without further purification. The Pd/C-

\section{Scheme $1^{a}$}

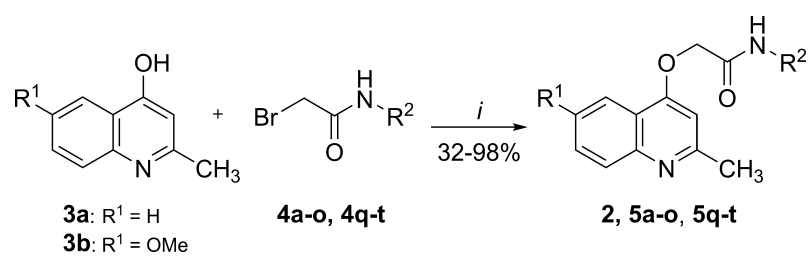

${ }^{a}$ Reaction conditions: (i) DMF, $\mathrm{K}_{2} \mathrm{CO}_{3}, 25{ }^{\circ} \mathrm{C}, 16 \mathrm{~h}$. catalyzed hydrogenation reaction of 50 yielded the 4-amino derivative $5 \mathrm{p}$ with $32 \%$ yield. According to a previous report, ${ }^{14}$ when the 2-methyl group was substituted with hydrogen, the $\mathrm{N}$-alkylation was obtained with high chemoselectivity, leading to compound 7 with $72 \%$ yield (Scheme 2 ).

Scheme $2^{a}$

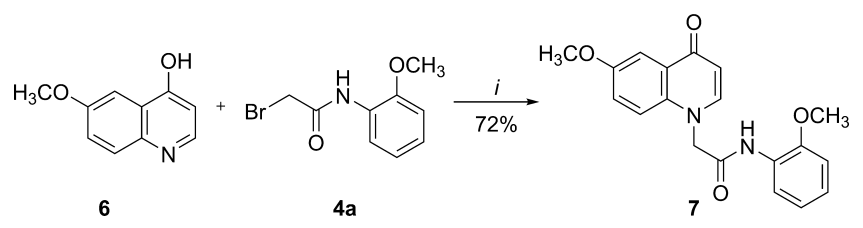

${ }^{a}$ Reaction conditions: (i) DMF, $\mathrm{K}_{2} \mathrm{CO}_{3}, 25{ }^{\circ} \mathrm{C}, 16 \mathrm{~h}$.

All synthesized compounds showed the proposed structures based on spectroscopic and spectrometric data (Supporting Information). In addition, a crystal structure of 2-(quinolin-4yloxy)acetamide 5s was determined by X-ray diffraction. ${ }^{15}$ According to NMR data, $\mathrm{N}$-arylacetamide was attached to the quinoline ring via a 4-hydroxyl group (Figure 2). The crystal data and parameters for structure refinement are summarized in Table S1 (Supporting Information).

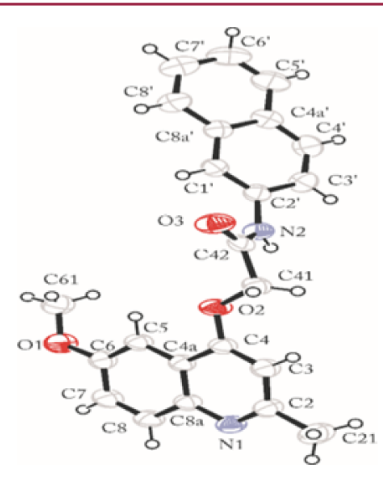

Figure 2. Structure of compound 5s with atomic labeling. Hydrogen atoms are represented by circles of arbitrary radii.

The synthesized compounds were evaluated in a whole-cell assay against $M$. tuberculosis strain $\mathrm{H} 37 \mathrm{Rv}$ using isoniazid (INH) as the standard drug. ${ }^{10,16}$ The antibacterial screening revealed that most of the 2-(quinolin-4-yloxy)acetamides tested showed MICs at submicromolar concentrations (except compounds $\mathbf{5 a}, \mathbf{5 g}-\mathbf{h}$, and $\mathbf{5 n}-\mathbf{q}$ ) and were more potent than the first-line anti-TB drug INH (Table 1). In general, electron withdrawing groups yielded compounds with decreased activity, while bulky lipophilic substituents improved the antimycobacterial action of the synthesized compounds. The lead compound 2 presented an MIC value of $0.44 \mu \mathrm{M}$. In an attempt to determine the necessity of the methyl group attached at the 2-position on the quinoline ring of 2 , we tried to obtain the $O$-alkylated derivative of 6-methoxyquinolin-4-ol (6). Unfortunately, the $N$-alkylated compound 7 was the only structure isolated. This compound showed MIC > $31 \mu \mathrm{M}$, denoting the importance of $\mathrm{N}$-arylamide at the 4-position of the quinoline ring and/or the presence of the 2-methyl group for activity. As the 6-methoxy-2-methylquinolin-4-ol (3b) was devoid of any activity under the tested conditions (data not shown), the former proposal appears more plausible. Additionally, the 6-methoxy group was found to be pivotal for activity because compound 5a exhibited an MIC > $29 \mu \mathrm{M}$. However, 
Table 1. ClogP Values, in Vitro Activity against M. tuberculosis H37Rv, Drug-Resistant Clinical Isolates, and Intracellular Activity of 2-(Quinolin-4-yloxy)acetamides against the M. tuberculosis H37Rv Strain in Infected Macrophages<smiles>[R]NC(=O)COc1cc(C)nc2ccc([R])cc12</smiles>

2, 5a-t

\begin{tabular}{|c|c|c|c|c|c|c|c|c|}
\hline Entry & $\mathbf{R}^{1}$ & $\mathbf{R}^{2}$ & $\operatorname{Clog}^{P^{a}}$ & $\begin{array}{c}\text { MIC H37Rv } \\
(\mu \mathrm{M})\end{array}$ & $\begin{array}{c}\text { MIC RS-036 } \\
(\mu \mathrm{M})\end{array}$ & $\begin{array}{c}\text { MIC RS-032 } \\
(\mu \mathrm{M})\end{array}$ & $\begin{array}{c}\text { MIC PE-003 } \\
\quad(\mu \mathrm{M})\end{array}$ & $\begin{array}{c}\text { Mean } \log _{10} \\
\text { CFU/Well } \pm \\
\text { SEM }^{\mathrm{b}}\end{array}$ \\
\hline 2 & $\mathrm{MeO}$ & $\mathrm{MeO}-2-\mathrm{C}_{6} \mathrm{H}_{4}$ & 3.32 & 0.44 & 0.44 & 0.88 & 0.06 & $1.61 \pm 0.09^{* * *}$ \\
\hline $5 \mathbf{a}$ & $\mathrm{H}$ & $\mathrm{MeO}-2-\mathrm{C}_{6} \mathrm{H}_{4}$ & 3.05 & $>29$ & - & - & - & - \\
\hline $5 \mathrm{~b}$ & $\mathrm{MeO}$ & $\mathrm{Ph}$ & 3.83 & 0.48 & 0.48 & 1.93 & 0.24 & - \\
\hline $5 \mathrm{sc}$ & $\mathrm{MeO}$ & $\mathrm{MeO}-3-\mathrm{C}_{6} \mathrm{H}_{4}$ & 3.91 & 0.88 & 1.77 & 7.08 & 0.44 & - \\
\hline $5 d$ & $\mathrm{MeO}$ & $\mathrm{MeO}-4-\mathrm{C}_{6} \mathrm{H}_{4}$ & 3.91 & 0.44 & 0.44 & 0.88 & 0.06 & - \\
\hline 5 e & $\mathrm{MeO}$ & $(\mathrm{MeO})_{2}-2,4-\mathrm{C}_{6} \mathrm{H}_{3}$ & 3.34 & 0.15 & 0.41 & 0.81 & 0.20 & $1.61 \pm 0.23^{* * *}$ \\
\hline $5 f$ & $\mathrm{MeO}$ & Me-2- $\mathrm{C}_{6} \mathrm{H}_{4}$ & 3.68 & 0.46 & 0.46 & 0.93 & 0.11 & $2.09 \pm 0.05$ \\
\hline $5 \mathrm{~g}$ & $\mathrm{MeO}$ & Me-6-Et-2- $\mathrm{C}_{6} \mathrm{H}_{3}$ & 3.84 & $>27$ & - & - & - & - \\
\hline $5 \mathrm{~h}$ & $\mathrm{MeO}$ & $\mathrm{F}_{3} \mathrm{C}-3-\mathrm{C}_{6} \mathrm{H}_{4}$ & 5.17 & 6.39 & - & - & - & - \\
\hline $5 \mathbf{i}$ & $\mathrm{MeO}$ & $\mathrm{F}_{3} \mathrm{C}-4-\mathrm{C}_{6} \mathrm{H}_{4}$ & 5.17 & 0.80 & 0.80 & 1.60 & 0.1 & $1.89 \pm 0.08^{* *}$ \\
\hline $5 \mathbf{j}$ & $\mathrm{MeO}$ & $\begin{array}{ll}\mathrm{Cl}-2-\mathrm{C}_{6} \mathrm{H}_{4} \\
\end{array}$ & 3.95 & 0.44 & 0.44 & 1.75 & 0.11 & $1.75 \pm 0.07^{* * *}$ \\
\hline $5 \mathbf{k}$ & $\mathrm{MeO}$ & Cl-3- $\mathrm{C}_{6} \mathrm{H}_{4}$ & 4.80 & 0.44 & 0.87 & 3.50 & 0.22 & $2.12 \pm 0.11$ \\
\hline 51 & $\mathrm{MeO}$ & $\mathrm{Cl}-4-\mathrm{C}_{6} \mathrm{H}_{4}$ & 4.80 & 0.44 & 0.44 & 0.87 & 0.06 & $1.73 \pm 0.07^{* * *}$ \\
\hline $5 \mathrm{~m}$ & $\mathrm{MeO}$ & $\mathrm{Br}-4-\mathrm{C}_{6} \mathrm{H}_{4}$ & 4.95 & 0.1 & 0.39 & 0.78 & 0.05 & $1.87 \pm 0.09^{* *}$ \\
\hline $5 n$ & $\mathrm{MeO}$ & $\mathrm{O}_{2} \mathrm{~N}-2-\mathrm{C}_{6} \mathrm{H}_{4}$ & 3.67 & 6.79 & - & - & - & - \\
\hline 50 & $\mathrm{MeO}$ & $\mathrm{O}_{2} \mathrm{~N}-4-\mathrm{C}_{6} \mathrm{H}_{4}$ & 4.13 & 6.79 & - & - & - & - \\
\hline $5 p$ & $\mathrm{MeO}$ & $\mathrm{H}_{2} \mathrm{~N}-4-\mathrm{C}_{6} \mathrm{H}_{4}$ & 2.61 & 7.39 & - & - & - & - \\
\hline $5 q$ & $\mathrm{MeO}$ & $\mathrm{Bn}$ & 3.86 & 1.85 & 1.85 & 3.71 & 0.46 & $1.71 \pm 0.11^{* * *}$ \\
\hline $5 \mathrm{r}$ & $\mathrm{MeO}$ & 1-Naphthyl & 5.01 & 0.21 & - & - & - & \\
\hline $5 s$ & $\mathrm{MeO}$ & 2-Naphthyl & 5.01 & 0.05 & 0.10 & 0.84 & 0.05 & $1.93 \pm 0.10^{*}$ \\
\hline 5 t & $\mathrm{MeO}$ & & 3.89 & 0.42 & 0.85 & 3.41 & 0.21 & $1.77 \pm 0.14^{* *}$ \\
\hline INH & - & - & -0.67 & 1.46 & $>70.0$ & $>70.0$ & $>70.0$ & - \\
\hline RIF & - & - & 3.71 & - & - & - & - & $1.58 \pm 0.14^{* * *}$ \\
\hline UNT & - & - & & - & - & - & - & $2.50 \pm 0.15$ \\
\hline
\end{tabular}

${ }^{a}$ ClogP calculated by ChemBioDraw Ultra version 13.0.0.3015. ${ }^{b}$ Data are expressed as the means \pm SEM of triplicates for each compound tested at 5 $\mu \mathrm{M}$. INH, isoniazid. RIF, Rifampin. UNT, Untreated. $* P<0.05$, $* * P<0.01$, $* * * P<0.001$ compared with the untreated group (Dunnett post-test).

when the $N$-phenylacetamide portion was considered, the methoxy group did not appear to be imperative to antimycobacterial activity because compound $\mathbf{5 b}$ exhibited an MIC value of $0.48 \mu \mathrm{M}$, which differed only slightly from 2 (0.44 $\mu \mathrm{M})$.

Additionally, the change from the 2- to 4-position did not alter the activity because the 4-methoxy derivative $\mathbf{5 d}$ exhibited an identical MIC value of $0.44 \mu \mathrm{M}$. However, the MIC of 2(quinolin-4-yloxy)acetamide 5c was $0.88 \mu \mathrm{M}$, denoting that positioning the methoxy group at the 3-position of the benzyl ring decreased the potency of the compound 2 -fold. These data encouraged us to synthesize the 2,4-dimethoxy derivative $\mathbf{5 e}$, which showed a MIC value of $0.15 \mu \mathrm{M}$. Compared with 2(quinolin-4-yloxy)acetamide 2, the disubstituted compound (5e) showed an improvement in the antimycobacterial activity of nearly 3 -fold. Changing the electron-donating group with 2- methyl, the potency was maintained because compound $\mathbf{5 f}$ showed a MIC of $0.46 \mu \mathrm{M}$. By contrast, the presence of an additional ethyl group at the ortho-position of the aryl ring $(\mathbf{5 g})$ greatly decreased the activity of this compound (MIC > 27 $\mu \mathrm{M})$. Trifluoromethyl substituents at the 3- (5h) and 4positions (5i) yielded MICs of 6.39 and $0.80 \mu \mathrm{M}$, respectively. Notably, independent of the position of the chloro group attached to the aryl group in compounds $5 \mathbf{j}-\mathbf{l}$, the MIC values were $0.44 \mu \mathrm{M}$. Increasing lipophilicity with bioisosteric replacement of 4-chloro by 4-bromo improved the inhibitory capacity toward M. tuberculosis $\mathrm{H} 37 \mathrm{Rv}$, resulting in a MIC of $0.10 \mu \mathrm{M}$ for compound $\mathbf{5 m}$. Compared with the lead compound 2, the 2-(quinolin-4-yloxy)acetamide $5 \mathrm{~m}$ was 4.4fold more potent against the bacilli. By contrast, nitrosubstituted compounds $\mathbf{5 n}$ and 5o exhibited an identical MIC of $6.79 \mu \mathrm{M}$, which was approximately 16 -fold less effective than 
the 2-methoxy derivative 2 . This potency decrease may be related to electronic and/or molecular charge effects. The 4amino-substituted compound $5 \mathrm{p}$ also did not show improved activity and presented a MIC of $7.39 \mu \mathrm{M}$. Additionally, displacing the position of the aryl ring by inserting a benzyl group resulted in decreased activity of structure $\mathbf{5 q}$ when compared with the phenyl counterpart $\mathbf{5 b}$. To improve the molecular volume and hydrophobicity (Table 1 ) at the $\mathrm{N}$ arylamide portion, the 1- and 2-naphthyl substituted compounds (5r and 5s) were synthesized. Compound 5s was the most active structure tested from the 2-(quinolin-4-yloxy)acetamide series here described with an MIC of $0.05 \mu \mathrm{M}$, leading to a potency 8.8-fold higher than compound 2 . Compared with INH, the 2-(quinolin-4-yloxy)acetamide 5s was about 30-fold more potent. By contrast, 1-naphthyl derivative $5 \mathrm{r}$ exhibited a MIC value $0.42 \mu \mathrm{M}$ denoting that hydrophobicity can explain only part of antimycobacterial elicited by compounds. Finally, benzo $[d][1,3]$ dioxole derivative 5t yielded a similar potency compared with lead molecule 2 with an MIC of $0.42 \mu \mathrm{M}$.

Using a threshold of $2 \mu \mathrm{M}$ for the MIC values, 142 (quinolin-4-yloxy)acetamides (2, 5b-f, $\mathbf{5 i}-\mathbf{m}, \mathbf{5 q}$, and $\mathbf{5 s}-\mathbf{t}$ ) were selected for both inhibitory activity of three clinical isolates (RS-036, RS-032, and PE-003) and viability studies using Vero and HaCat cells (Table S2, Supporting Information). Due to antimycobacterial activity of compounds 5r and 5s and their structural similarity, only the 2-naphthylderivative (5s) was selected. The RS-036 and RS-032 are isoniazid monoresistant strains that contain mutations in the inhA regulatory regions $\mathrm{C}(-15) \mathrm{T}$ and $k a t G \mathrm{~S} 315 \mathrm{~T}$, respectively. ${ }^{17}$ The PE-003 strain is a multidrug-resistant clinical isolate that is resistant to isoniazid, rifampin, etambutol, and streptomycin and contains a mutation in the inhA regulatory region $\mathrm{C}(-15) \mathrm{T} .^{18}$ In general, potency in the submicromolar range was maintained for the evaluated compounds (Table 1$)$. The three most active structures were the 2,4-dimethoxy (5e), 4-bromo (5m), and 2-naphthyl (5s) substituted compounds (Figure S3, Supporting Information). From the data shown in Table 1, it can be concluded that the mutation in the kat $G$ gene observed in the RS-032 strain decreased the activity of the compounds from 2- to 16-fold based on the MIC values. However, participation of the katG gene product in the mechanism of action of 2-(quinolin-4-yloxy)acetamides should be carefully considered because targeted sequencing was employed to evaluate the genome mutations involved in drug resistance, contrary to whole genome sequencing. Accordingly, it cannot be discarded that mutations in other regions of the bacilli genome may be involved in the mechanism of drug resistance. Cellular viability was evaluated after exposing the Vero and $\mathrm{HaCat}$ cell lineages to the compounds for $72 \mathrm{~h}^{19}$ Except for 5s, in vitro incubation of the compounds at the concentration of $20 \mu \mathrm{M}$ did not significantly affect the cell viability of either cell line tested (Table S2, Supporting Information). Additionally, the compounds were screened in vitro against Escherichia coli (ATCC 25922), Pseudomonas aeruginosa (ATCC 27853), Staphylococcus aureus (ATCC 25923), and Acinetobacter baumannii (ATCC BAA 747). At the $20 \mu \mathrm{M}$ concentration, the 2-(quinolin-4-yloxy)acetamides $\mathbf{2}, \mathbf{5 b}-\mathbf{f}, \mathbf{5 i}-\mathbf{m}, \mathbf{5 q}$, and $\mathbf{5 s}-\mathbf{t}$ did not show antimicrobial activity, exhibiting selective action against $\mathrm{Mtb}$ (data not shown).

To evaluate intracellular activity, compounds were chosen based on their cytotoxic effects (concentration of $5 \mu \mathrm{M}$ ) on
RAW 264.7 cells. $^{20}$ The compounds $2, \mathbf{5 e}-\mathbf{f}, \mathbf{5 i}-\mathbf{m}, \mathbf{5 q}$, and 5s-t did not interfere with cell viability at the tested concentration (Table S3, Supporting Information) and were then evaluated for their intracellular activities (Table 1). The rifampin $(5 \mu \mathrm{M})$-treated group showed a decrease of $0.92 \log _{10}$ $(P<0.001)$ in CFU counts compared with the untreated control (Table 1). Unfortunately, compounds $\mathbf{5} \mathbf{f}$ and $\mathbf{5 k}$ did not show intracellular activity. However, treatment with compounds $\mathbf{2}, \mathbf{5 e}, \mathbf{5 i}-\mathbf{j}, \mathbf{5 1}-\mathbf{m}, \mathbf{5 q}$, and $\mathbf{5 s}-\mathbf{t}$ resulted in statistically significant decreases in CFU units compared with the untreated control (Table 1). Notably, compounds $\mathbf{2}$, 5e, $\mathbf{5 j}$, $\mathbf{5 l}$, and $\mathbf{5 q}$ exhibited intracellular activity closely related to rifampin. These findings revealed that the 2-(quinolin-4-yloxy)acetamides possess physicochemical features that permit crossing cellular and mycobacterial barriers to inhibit the Mtb growth inside macrophages.

Beyond their early activities, basic in vitro and in vivo profiling of the compounds $\mathbf{2}, \mathbf{5 e}, \mathbf{5 m}$, and $\mathbf{5 s}$ were determined (Table S4, Supporting Information). Thermodynamic solubility was evaluated in aqueous solutions with $\mathrm{pH}$ of $1.5,4$, and 7.4. As expected, the solubility of compounds was markedly higher at $\mathrm{pH} \quad 1.5$ than at a physiological $\mathrm{pH}$. 2-(Quinolin-4-yloxy)acetamides $\mathbf{5 e}, \mathbf{5 m}$, and $\mathbf{5 s}$ exhibited solubilities ranging from 0.03 to $2.1 \mathrm{mM}$ at $\mathrm{pH} 1.5$ and values of less than $4.4 \mu \mathrm{M}$ at $\mathrm{pH}$ 7.4. Although chemical modifications have reduced aqueous solubility of compounds throughout the course of our lead optimization efforts, at $\mathrm{pH} \mathrm{1.5,} \mathrm{the} \mathrm{compounds} 5 \mathrm{e}$ and $5 \mathrm{~s}$ showed solubility higher than $100 \mu \mathrm{M}$, which has been described as a cutoff in early drug discovery. ${ }^{21}$ Furthermore, the in vitro intrinsic clearance analysis revealed that 2-(quinolin4-yloxy)acetamides $5 \mathrm{e}$ and $\mathbf{5 m}$ exhibit moderate metabolic stability, whereas compound 5s displays high rates of metabolism. In addition, compared with lead molecule 2 , the compounds $5 \mathbf{e}$ and $\mathbf{5 m}$ showed an improvement of in vitro halflife. Nevertheless, potential drug-drug interactions were evaluated using human CYP450 inhibition studies. Compounds 5e, 5m, and 5s did not show any significant inhibition $\left(\mathrm{IC}_{50}\right.$ value $<10 \mu \mathrm{M})^{21}$ to the evaluated liver enzymes, denoting a minimal risk of metabolic drug-drug interactions. Finally, the most active compounds $\mathbf{5 e}, \mathbf{5 m}$, and $\mathbf{5 s}$ were subjected to potential cardiac toxicity evaluation in a zebrafish (Danio rerio) model. ${ }^{22}$ Compounds were analyzed with heart rate variations and were found to be safe to the embryos at 1 and $5 \mu \mathrm{M}$. By contrast, when tested at $20 \mu \mathrm{M}, 2$-(quinolin-4-yloxy)acetamides 5e, $5 \mathrm{~m}$, and $\mathbf{5 s}$ significantly reduced heart rate compared with control. Moreover, embryo survival was also reduced after $72 \mathrm{~h}$ of exposition to $20 \mu \mathrm{M}$ of compound $\mathbf{5 s}$ (data not shown). It is important to mention that selectivity index of compound $5 \mathrm{~s}$ was at least $>100$ considering a MIC value of $0.05 \mu \mathrm{M}$ and both eukaryotic cell viability and cardiac toxicity profiles.

In summary, in this work we demonstrated the synthesis of a series of 2-(quinolin-4-yloxy)acetamides and their anti-TB activity in vitro. The simplicity, easily accessible reactants and reagents, reasonably good yields (32-98\%), and high purity make this synthetic method attractive. In addition, the synthesized compounds showed potent and selective activity against drug-sensitive and drug-resistant Mtb strains as well as activity in a macrophage-infected model. The data described in this study reveal that this class of compounds may furnish promising candidates for future development of novel drugs for TB treatment. To achieve this objective, new structural modification and/or pharmaceutical formulation studies should be performed as low aqueous solubility coupled with rapid 
metabolism are often key factors in poor pharmacokinetics. Studies to identify the target(s) of 2-(quinolin-4-yloxy)acetamides antimycobacterial action are in progress, and these data will be communicated in the future.

\section{ASSOCIATED CONTENT}

\section{S Supporting Information}

The Supporting Information is available free of charge on the ACS Publications website at DOI: 10.1021/acsmedchemlett.5b00324.

Synthetic procedures, analytical data, crystal data and details of the data collection, and bioassay protocols (PDF)

\section{AUTHOR INFORMATION}

\section{Corresponding Authors}

*Phone/Fax: +55 513320 3629. E-mail: diogenes@pucrs.br. *Phone/Fax: +55 513320 3629. E-mail: pablo.machado@ pucrs.br.

\section{Author Contributions}

The manuscript was written through contributions of all authors.

\section{Funding}

This work was supported by funds from the National Institute of Science and Technology on Tuberculosis (INCT-TB), Decit/SCTIE/MS-MCT-CNPq-FNDCT-CAPES (Brazil) to D.S.S. and L.A.B. C.D.B., D.F.B., M.M.C., L.A.B., and D.S.S are Research Career Awardees of the National Research Council of Brazil $(\mathrm{CNPq})$. The fellowships from $\mathrm{CNPq}$ (K.P., V.R.-J., and E.S.G.), CAPES (A.D.V. and B.L.A.), and FAPERGS (R.V.T.) are also acknowledged.

\section{Notes}

The authors declare no competing financial interest.

\section{REFERENCES}

(1) World Health Organization. Global tuberculosis report 2015. http://www.who.int/tb/publications/global_report/en/ (accessed in December 2015).

(2) Gandhi, N. R.; Nunn, P.; Dheda, K.; Schaaf, H. S.; Zignol, M.; Soolingen, D. v.; Jensen, P.; Bayona, J. Multidrug-resistant and extensively drug-resistant tuberculosis: a threat to global control of tuberculosis. Lancet 2010, 375, 1830-1843.

(3) Pawlowski, A.; Jansson, M.; Skold, M.; Rottenberg, M. E.; Kallenius, G. Tuberculosis and HIV Co-infection. PLoS Pathog. 2012, $8,1-7$.

(4) Zhang, Y.; Yew, W. W.; Barer, M. R. Targeting persisters for tuberculosis control. Antimicrob. Agents Chemother. 2012, 56, 22232230.

(5) Hoffner, S. Unexpected high levels of multidrug-resistant tuberculosis present new challenges for tuberculosis control. Lancet 2012, 380, 1367-1369.

(6) Palomino, J. C.; Martin, A. TMC207 becomes bedaquiline, a new anti-TB drug. Future Microbiol. 2013, 8, 1071-1080.

(7) Avorn, J. Approval of a tuberculosis drug based on a paradoxical surrogate measure. J. Am. Med. Assoc. 2013, 309, 1349-1350.

(8) Shandil, R. K.; Jayaram, R.; Kaur, P.; Gaonkar, S.; Suresh, B. L.; Mahesh, B. N.; Jayashree, R.; Nandi, V.; Bharath, S.; Balasubramanian, V. Moxifloxacin, ofloxacin, sparfloxacin, and ciprofloxacin against Mycobacterium tuberculosis: Evaluation of in vitro and pharmacodynamics indices that best predict in vivo efficacy. Antimicrob. Agents Chemother. 2007, 51, 576-582.

(9) Singh, S.; Kaur, G.; Mangla, V.; Gupta, M. K. Quinoline and quinolones: promising scaffolds for future antimycobacterial agents. $J$. Enzyme Inhib. Med. Chem. 2015, 30, 492-504.
(10) Ballell, L.; Bates, R. H.; Young, R. J.; Alvarez-Gomez, D.; Alvarez-Ruiz, E.; Barroso, V.; Blanco, D.; Crespo, B.; Escribano, J.; Gonzalez, R.; Lozano, S.; Huss, S.; Santos-Villarejo, A.; Julio MartinPlaza, J.; Mendoza, A.; Jose Rebollo-Lopez, M.; Remuinan-Blanco, M.; Luis Lavandera, J.; Perez-Herran, E.; Javier Gamo-Benito, F.; Francisco Garcia-Bustos, J.; Barros, D.; Castro, J. P.; Cammack, N. Fueling Open-Source Drug Discovery: 177 Small-Molecule Leads against Tuberculosis. ChemMedChem 2013, 8, 313-321.

(11) Craig, P. N. Interdependence between physical parameters and selection of substituent groups for correlation studies. J. Med. Chem. 1971, 14, 680-684.

(12) Macpherson, I. S.; Kirubakaran, S.; Gorla, S. K.; Riera, T. V.; D'Aquino, J. A.; Zhang, M.; Cuny, G. D.; Hedstrom, L. The structural basis of cryptosporidium-specific IMP dehydrogenase inhibitor selectivity. J. Am. Chem. Soc. 2010, 132, 1230-1231.

(13) Pissinate, K.; Rostirolla, D. C.; Pinheiro, L. M.; Suryadevara, P.; Yogeeswari, P.; Sriram, D.; Basso, L. A.; Machado, P.; Santos, D. S. Synthesis and evaluation of thiazolyl- $1 H$-benzo[d]imidazole inhibitors of Mycobacterium tuberculosis inosine monophosphate dehydrogenase. J. Braz. Chem. Soc. 2015, 26, 1357-1366.

(14) Lilienkampf, A.; Mao, J.; Wan, B.; Wang, Y.; Franzblau, S. G.; Kozikowski, A. P. Structure-activity relathionships for a series of quinoline-based compounds active against replicanting and nonreplicating Mycobacterium tuberculosis. J. Med. Chem. 2009, 52, 21092118.

(15) CCDC number 1416527 contains the supplementary crystallographic data for compound reported in this paper. These data can be obtained free of charge via www.ccdc.cam.ac.uk/conts/retrieving.html (or from the Cambridge Crystallographic Data Centre, 12, Union Road, Cambridge CB2 1EZ, UK; fax: + 441223 336033).

(16) Palomino, J. C.; Martin, A.; Camacho, M.; Guerra, H.; Swings, J.; Portaels, F. Resazurin microtiter assay plate: Simple and inexpensive method for detection of drug resistance in Mycobacterium tuberculosis. Antimicrob. Agents Chemother. 2002, 46, 2720-2722.

(17) Maschmann, R. A.; Spies, F. S.; Nunes, L. S.; Ribeiro, A. W.; Machado, T. R. M.; Zaha, A.; Rossetti, M. L. R. Performance of the GenoType MTBDRplus assay directly on sputum specimens from Brazilian patients with tuberculosis treatment failure or relapse. J. Clin. Microbiol. 2013, 51, 1606-1608.

(18) Costa, E. R. D.; Ribeiro, M. O.; Silva, M. S. N.; Arnold, L. S.; Rostirolla, D. C.; Cafrune, P. I.; Espinoza, R. C.; Palaci, M.; Telles, M. A.; Ritacco, V.; Suffys, P. N.; Lopes, M. L.; Campelo, C. L.; Miranda, S. S.; Kremer, K.; Silva, P. E. A.; Fonseca, L. S.; Ho, J. L.; Kritski, A. L.; Rossetti, M. L. R. Correlations of mutations in katG, oxyR-ahpC and inhA genes and in vitro susceptibility in Mycobacterium tuberculosis clinical strains segregated by spoligotype families from tuberculosis prevalent countries in South America. BMC Microbiol. 2009, 9, 39.

(19) Tuberculosis Antimicrobial Acquisition \& Coordinating Facility (TAACF): Description of TAACF Assays.

(20) Rodrigues-Junior, V. S.; dos Santos, A. A. J.; Villela, A. D.; Belardinelli, J. M.; Morbidoni, H. R.; Basso, L. A.; Campos, M. M.; Santos, D. S. IQG-607 abrogates the synthesis of mycolic acids and displays intracellular activity against Mycobacterium tuberculosis in infected macrophages. Int. J. Antimicrob. Agents 2014, 43, 82-85.

(21) Hughes, J. P.; Rees, S.; Kalindjian, S. B.; Philpott, K. L. Principles of early drug discovery. Br. J. Pharmacol. 2011, 162, 12391249.

(22) Selderslaghs, I. W. T.; Rompay, A. R. V.; Coen, W. D.; Witters, H. E. Development of a screening assay to identify teratogenic and embryotoxic chemicals using the zebrafish embryo. Reprod. Toxicol. 2009, 28, 308-320. 